\title{
ANDRÓMEDA ou uma Subtil História da Televisão Pública Italiana
}

\author{
Rita Luís
}

Instituto de História Contemporânea / Nova-FCSH

ritaluis@fcsh.unl.pt

https://orcid.org/0000-0002-7757-2264

A exposição ANDRÓMEDA, de Luciana Fina, esteve aberta ao público gratuitamente entre 21 de maio e 1 de agosto, nas Carpintarias de São Lázaro em Lisboa. Oficializadas enquanto associação em 2014, as Carpintarias de São Lázaro dispõem, desde 2019, de um espaço físico situado numa centenária carpintaria sita na rua de São Lázaro, entre o Campo de Santana e o Martim Moniz. Enquanto centro cultural, a sua missão não se limita à função expositiva, servindo também de acolhimento à criação, um compromisso assumido perante a Câmara Municipal de Lisboa, que lhes cedeu o espaço. ${ }^{1}$

Inaugurada imediatamente após o final do segundo confinamento em Portugal, a exposição de Luciana Fina reflete a frescura que a sala de cinema nos traz em dias de calor intenso e remete para os espaços interiores vazios a que a pandemia nos habituou. Uma sala escura, despojada, oferece-nos pequenas pistas, primeiro técnicas, depois imagéticas, sobre o motivo que ali nos trouxe: a introdução do segundo canal na Itália dos anos 60 , formalmente plasmado na sala principal da exposição que alberga um díptico, formato expositivo característico de Fina, que coloca o espectador no lugar daquele que, de repente, passou a ter de decidir qual dos canais, a emitir em simultâneo, iria assistir. Luciana Fina é uma artista italiana (n. Bari, 1962) que trabalha, desde 1991, em Portugal, dedicando-se, de uma e outra forma, ao trabalho

\footnotetext{
1 Mais informação sobre as Carpintarias de São Lázaro pode ser encontrada no seu site: https://www.carpintariasdesaolazaro.pt/. Última visualização a 1 de Outubro de 2021.
} 
com/sobre os meios audiovisuais, do cinema ao design gráfico, tendo sempre a imagem como denominador comum.

ANDRÓMEDA remete para a época que Stephen Gundle (1997) classificou como a primeira fase da televisão italiana (1954-1974) e tem a capacidade de evocar subtilmente as facetas sociopolíticas, os aspectos tecnológicos, as relações entre a produção e o consumo televisivo, bem como as discussões teóricas e políticas com estes relacionados. A exposição de Luciana Fina aborda, especificamente, a segunda etapa deste processo, quando Itália, que viu surgir a televisão em meados dos anos 50, deixou de ser uma economia baseada na produção agrícola e se assumiu como um país industrializado que inaugura o seu segundo canal televisivo. A chamada década do "milagre económico" coincidiu com o desenvolvimento da televisão em Itália, sendo disputado se a relação que se estabelece entre ambos é de correlação ou causalidade (Foot 2002). A causalidade evocada evidencia este meio como organizador da estrutura social italiana, enfatizando o seu papel na unificação linguística, cultural e social do país. Nesta perspetiva, a televisão é apresentada como um meio que mostrou ao Sul as formas de vida do Norte, materializando assim as possibilidades da migração interna. Contudo, esta tendência interpretativa deixa de lado factores importantes nas transformações que marcaram esta década (Foot 2002, Gundle 1997): o papel dos meios audiovisuais pré-existentes, como a rádio e o cinema; outras formas de cultura de massas, como o desporto e o turismo; as próprias migrações; e, sobretudo, a extensão e democratização do sistema educativo e o consequente aumento da literacia, reforçada, é certo, pela Telescoula [Telescola]. Isola-se e destaca-se a importância de um meio numa transformação tamanha, invisibilizando o sistema do qual a televisão é parte integrante (Ortoleva 1996).

Neste sentido, a exposição de Luciana Fina acaba por seguir a tendência de deixar o sistema fora de plano, embora introduza a importante relação da televisão (e das suas formas de fazer) com o cinema e com o campo artístico. Grosso modo, ANDRÓMEDA pode dividir-se em três elementos indissociáveis numa abordagem historiográfica da televisão: o domínio da tecnologia e o seu impacto na (re)estruturação da vida quotidiana, o papel e os efeitos da televisão, remetendo, neste caso, para a história da Itália do segundo pós-guerra e, finalmente, as discussões teóricas, políticas e artísticas sobre esse mesmo papel e os efeitos da produção e do consumo televisivo na sociedade de então. 


\section{A antecâmara: o percurso tecnológico}

Relativamente lateralizado, à direita do primeiro painel da exposição, cujo percurso se inicia pela esquerda, encontramos um pequeno objecto, fulcral na alteração conceptual que a introdução de um segundo canal televisivo provocou: um proto-telecomando.

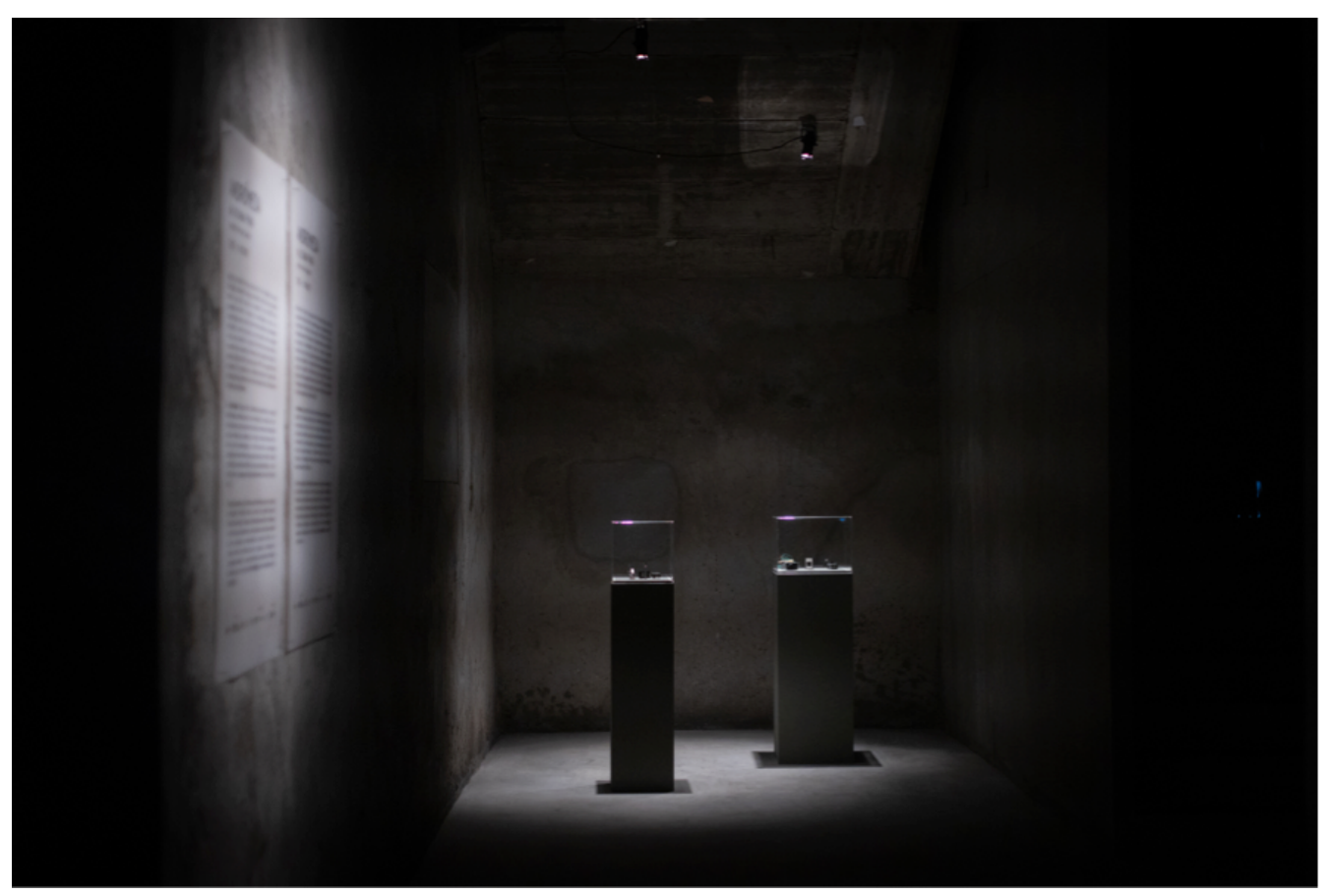

Imagem 1: ANDRÓMEDA, Luciana Fina, exposição Carpintarias de São Lázaro, Lisboa 2021. | Fotografia de Alípio Padilha.

A simultaneidade da emissão televisiva exigiu uma nova forma de ver televisão. A nível psicológico introduziu a possibilidade de alternar, fomentando o FOMO (fear of missing out), uma referência que a cultura popular encontrou para o mundo mediatizado em que vivemos, atualmente, através do smartphone. Fisicamente, o telecomando solucionou a necessidade de o espectador se aproximar do ecrã continuamente. A expansão do aparelho televisivo e, sobretudo, a sua entrada na esfera doméstica provocaram alterações na vida quotidiana, como a estruturação do tempo, influenciando, por exemplo, os horários e o formato das refeições. Mais à frente, a peça principal, o díptico que dá nome à exposição, alude a estas alterações, já que num dos ecrãs vamos observando uma criança à mesa, empunhando este antigo 
objecto, assistindo à televisão enquanto come, até finalmente adormecer.

\section{O segundo canal: uma nova Itália}

Como nos explica o pequeno vídeo institucional que abre o percurso expositivo, o segundo canal da Radio Televisione Italiana (RAI), inaugurado a 4 de novembro de 1961, terá um lançamento síncrono ao longo do território italiano, com 14 transmissores a emitir em simultâneo, demonstrando a tal unificação territorial, frequentemente adjudicada aos efeitos televisivos. Este pequeno vídeo anuncia-nos um novo país, já que a RAI, inaugurada a 1 de janeiro de 1954, foi uma emissão que se expandiu lentamente do Norte para o Sul. Aliás, embora as primeiras emissões experimentais remontem a 1939, estas estiveram circunscritas, numa segunda fase, a Milão (1952-1953). A importância desta cidade na história televisiva italiana tal que durante os primeiros anos (1954-1958) se considerou a capital da televisão (Ferrari e Giusto 2000). As formas de inauguração e implantação de ambos os canais mostram-nos, portanto, um país em duas etapas que, aparentemente, já não funciona a duas velocidades.

\section{Apocalíticos e integrados}

Após um percurso imagético através de um pequeno corredor, onde se encontram fotogramas e excertos de textos disponíveis em formato auditivo, entramos no espaço que alberga a peça central da exposição: o díptico “Andrómeda", cujo nome se inspira na mini-série de Vittorio Cottafavi para a RAI 1, A come Andromeda (1972), protagonizado por Nicoletta Rizzi. O díptico remete-nos para a simultaneidade que a inauguração de um segundo canal impôs, com a atenção do espectador a dividir-se entre o ecrã onde uma criança, sentada à mesa de jantar, assiste à televisão e um outro ecrã onde, sequencialmente, são emitidos excertos de programas que convocam debates e aproximações ao meio. A sequência é iniciada pelo programa "Zoom” (1966), no qual Umberto Eco conversa com Theodor W. Adorno sobre a função da televisão na sociedade contemporânea. Seguem-se-lhe séries de programas que se dedicavam a investigações sociais, como o "TV7" ("Un letto a la staczione", 1969) ou "Sapere" ("La Questione Femminile", de Virgilio Sabel, 1976). Estes excertos são intercalados por outros contendo anúncios, genéricos, intervalos, programas infantis, informativos, 
ficções, bem como esse grande evento televisivo da década de 60 a nível mundial que foi a aterragem do homem na lua, em 1969. No fundo, é-nos dada a grelha de programação que produzia novas formas de viver o quotidiano, com novos horários e novas formas de vestir, falar, encarar o lazer e perceber o mundo.

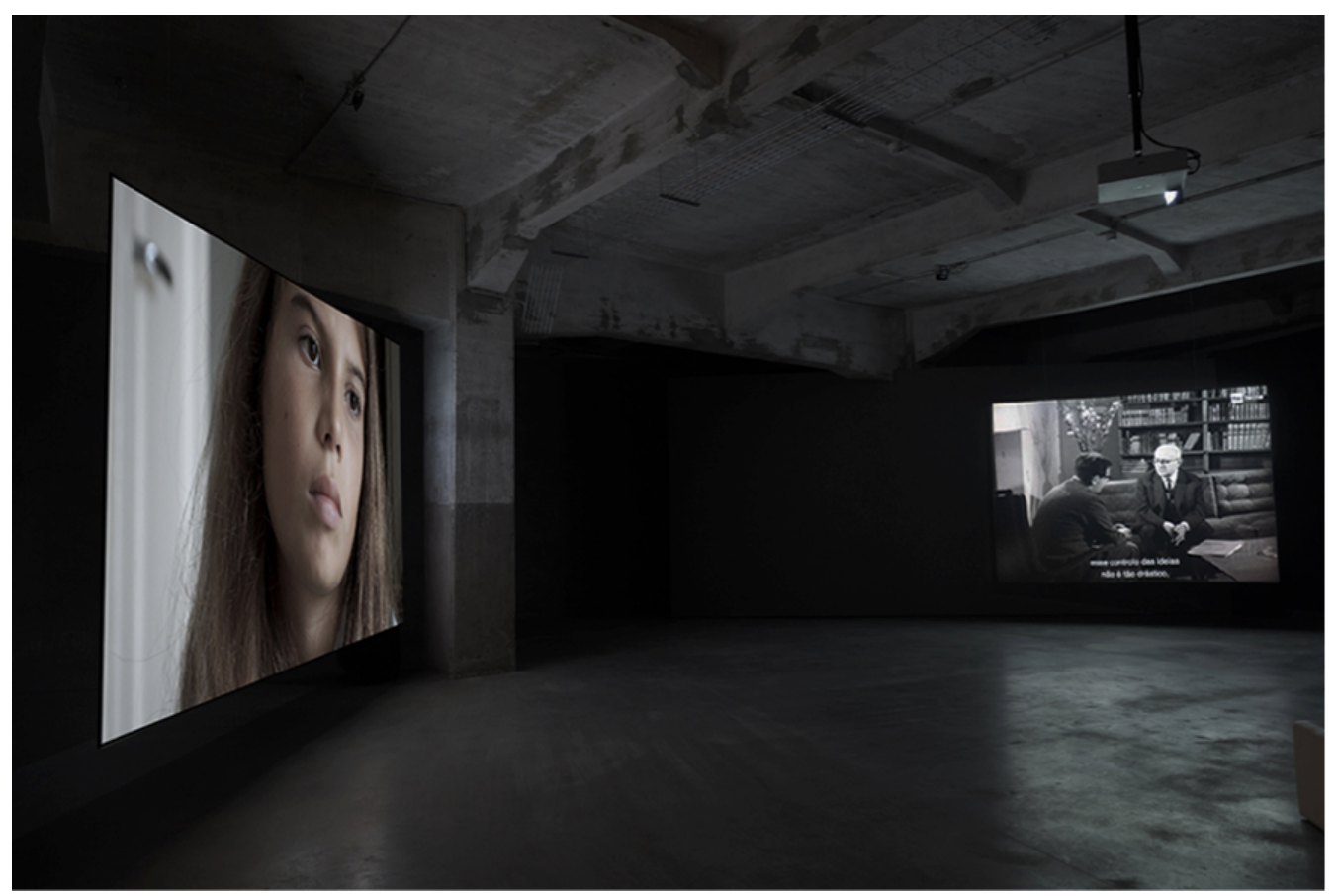

Imagem 2: ANDRÓMEDA, Luciana Fina, exposição Carpintarias de São Lázaro, Lisboa 2021. | Fotografia de Alípio Padilha.

Entre o corredor e o díptico vamos percorrendo a discussão sobre o lugar e os efeitos da televisão, sistematizada por Umberto Eco (1964) na oposição entre posições "apocalípticas" e "integradas". As primeiras, atribuídas àqueles que, maioritariamente à esquerda, ${ }^{2}$ alinhavam com a posição de Adorno (1954) relativamente à mercantilização inerente à cultura de massas, caracterizando a televisão, sobretudo o modelo comercial estado-unidense, como um instrumento incapaz de elevar o nível cultural das classes populares. As segundas - primeiramente

\footnotetext{
${ }^{2}$ ANDRÓMEDA não deixa de situar a complexa relação de Pier Paolo Pasolini com a televisão com uma leitura por Marcello Urgeghe de um excerto do guião de L'histoire du Soldat, Il capo della televisione (1972), um projeto inacabado com a sua morte em 1975 .
}

aniki Exposições e festivais de cinema | Exhibitions and film festivals 
adoptadas por católicos e de forma crescente por alguma esquerda $-^{3}$ reconheciam o impacto que o novo meio poderia ter como instrumento pedagógico, sobretudo se usado com objetivos de democratização social, cultural e artística (Eco 1964), mas também ao nível da inovação da linguagem artística, que Fina evoca remetendo para a emergência da videoarte.

Curiosamente, numa exposição que é subtilmente completa na abordagem desta fase do desenvolvimento televisivo, os vestígios do projeto televisivo católico "integrado", que foi o da RAI desta primeira fase (Scaglinoni 2015), nunca deixam de ser vestígios. Ou seja, tal como na generalidade dos países europeus, o monopólio audiovisual em Itália foi concedido a uma empresa: a Radio Audizioni Italia a partir de 1944, anteriormente Unione Radiofonica Italiana, uma entidade responsável pelas emissões radiofónicas e pela experimentação televisiva préguerra. Este monopólio deixou a televisão sob o controlo directo do governo até 1975 e, portanto, à mercê da forte influência católica através da Democracia Cristã, partido dominante durante esta fase, liderando governos de coligação de geometrias variáveis, incluindo nestas o Partito Socialista Italiano (1963).

O apelo que a televisão despertou no papa Pio XII e a influência que o Vaticano exercia (e exerce) na vida política e social italiana teve repercussão no projecto televisivo católico destas primeiras décadas (Scaglinoni 2015). Esta influência contou com alguns aspetos repressivos, ${ }^{4}$ mas o essencial do projecto televisivo católico caracterizava-se pelo reconhecimento do potencial pedagógico do meio.

Filiberto Guala, director geral da RAI entre 1954 e 1956, não queria transpor para a televisão o modelo radiofónico, que preconizava uma programação dedicada à pequena burguesia, com meios para adquirir um receptor televisivo. Num curto mandato conseguiu impor um novo modelo, através, sobretudo, de uma contratação em massa de jovens que permaneceram na RAI nas décadas seguintes (Scaglinoni, 2015).

\footnotetext{
${ }^{3}$ Caso de Roberto Rossellini, que Fina convoca no corredor, vocalizando um excerto do colóquio sobre Cinema e Televisão por ele organizado no festival de Cannes de 1977.

${ }^{4}$ Por exemplo, o código de censura Norme di autodisciplina per le transmissioni televisive, utilizado pela RAI desde 1954 foi redigido por Monsignor Albino Galleto (Centro Católico da Televisão), embora rapidamente tenha ficado conhecido como "código Guala", apelido do primeiro Diretor geral (1954-1956), Filiberto Guala (Scaglinoni, 2015).
} 
Estes, alinhados com um projeto católico de desenvolvimento nacional mais lato, que incluía a educação e a unificação entre a cultura popular e aquela considerada de elite, contribuíram para o papel pedagógico que a televisão desempenhou na disputa contra a hegemonia inicial das ideias comunistas e socialistas na Itália do segundo pós-guerra.

Ainda assim, a centralidade que Fina dá a A come Andromeda é significativa, já que esta produção faz parte de um tipo de programação, as minisséries, com que Ettore Bernabei, o sucessor de Guala, procurou reunir quotidianamente os telespectadores italianos à frente do televisor. São nestas entrelinhas da história e das imagens que percebemos, já a sair das Carpintarias, a subtileza na arte de Fina.

\section{Referências}

Adorno, Theodor W. 1954. "How to look at television." The Quarterly of Film, Radio and Television 8(3): 213-235.

Eco, Umberto. 1964. Apocalittici e Integrati: Comunicazioni di massa e teorie della cultura di massa. Milano: Bompiani

Ferrari, Ada e Giusto, Gaia, ed. 2000. Milano Città della Radio Televisione. Milan: Francoangeli.

Foot, John. 2002. "Inside the Magic Rectangle: Recent Research on the History of Television." Contemporary European History 11: 467475.

Gundle, Stephen. 1997. “Television in Italy.” Em: Television in Europe, organizado por James A. Coleman e Brigitte Rollet, 61-7. Exter: Intellect Books.

Ortoleva, Peppino. 1996. “A Geography of Media since 1945.” Em: Italian Cultural Studies. An Introduction, organizado por D. Forgacs e R. Lumley, 185-198. Oxford: Oxford University Press.

Scaglinoni, Massimo. 2015. "Television as a Project. The relation between public service broadcasting and Italian historical cultures (1954-1994)." Comunicazioni sociali 1: 7-21. 